\title{
SOCIODEMOGRAPHIC CHARACTERISTICS AS IT RELATES TO TRAVEL BEHAVIOUR IN SIDS: A CASE STUDY IN TRINIDAD
}

\author{
Leah Wright ${ }^{1 *}$, Trevor Townsend ${ }^{2}$ \\ ${ }^{1,2}$ Faculty of Engineering, The University of the West Indies, Trinidad \\ ${ }^{1}$ Email: leahwright05@gmail.com*(Corresponding author) \\ ${ }^{2}$ Email: trevor.townsend@sta.uwi.edu
}

\begin{abstract}
The objective of this research was to analyse the relationship between sociodemographic characteristics and the travel behaviour of Trinidadians. Many studies have shown that a relationship exists between the socio-economic and sociodemographic characteristics of an individual and their travel patterns. A better understanding of this relationship can influence transportation policy decisions and therefore, aid in improvement to the overall transportation structure. This understanding of travel behaviour is of particular importance in developing countries and SIDS, where there is limited geographical space, economic constraints and an influx of competitive unregulated paratransit modes into the transportation system. Trinidad, like other developing countries and SIDS, has a public transportation system that is dominated by paratransit modes. More notably, there is increasing penetration of illegally operated paratransit modes, that are aggressively competing in the market and gaining a lot of traction. Data was collected in January 2018 using a revealed preference survey of commuters' workbased tours in, Trincity, a middle-income housing area with good highway and public transportation access. Results showed that income, age, distance from workplace and gender all affect the likelihood of public transport usage as a primary mode of a work tour and there were gender-based differences in the incidence of walking as part of the tour. Additionally, although most public transportation users considered the government bus service as the safest and illegal paratransit services as the least safe, the usage of such services was more than five times that of the bus. The research points to important service and policy actions which need to be taken to encourage and support shifts to more sustainable modes.
\end{abstract}

Keywords: SIDS, Sociodemographic, Travel behavior.

\section{https://doi.org/10.47412/CPYI3065}

\section{Introduction}

Small island developing states (SIDS) have unique characteristics that expose them to different social, economic and development challenges. This is mainly due to their extremely small size and population, insularity, remoteness and limited areas, and natural resources [1, 2]. These characteristics have influenced the development of the quality of life in SIDS, especially in the field of transportation. Intensely few studies have focused on a better understanding of travel behaviour in SIDS. This study develops a mode choice model in the island of Trinidad, a Caribbean SIDS utilising revealed preference data based on travellers' subjective assessment of modal characteristics. 
The Republic of Trinidad \& Tobago is a twin-island state situated in the Caribbean region. The economy is with heavily based on oil \& gas, and the country has a relatively high GDP of $\$ 18,000$ USD per capita and a population of approximately 1.4 million people. Trinidad, the main island, with a total size of 5,128 square kilometres, is the most southern Caribbean island and is a few kilometres north of Venezuela. The island is classified into three main regions, North, Central and South Trinidad. A modern highway system connects these regions and a main road system that runs parallel to both the East-West and the North-South highways. In addition to this, there exists a Priority Bus Route (PBR) that runs along the East-West corridor in the North. The PBR is an exclusively high-occupancy vehicle route designed to provide relatively quick commutes for public transport passengers.

Due to its wealth, the country has a high per capita car ownership of over 500 vehicles per 1000 persons. This has led to significant problems of clogged roads, traffic congestion and long daily commutes. To add to the problem, there is considerable importation of used foreign cars into the island, making the availability of the private car easier to most persons [3].

The most commonly used public transportation modes in the island are the Public Transportation Service Corporation (PTSC) Bus, the maxi-taxi, the route taxi and the illegally operating PH taxi. Excluding the PTSC Bus, the modes listed can be classified as paratransit modes. Paratransit modes are informal public transportation modes. They have such characteristics that they lie between the conventional public transportation and the private car and provide a service to the general public [4-6]. These type of modes have shaped the transportation system and thus, included in the analysis.

The PTSC Bus is the single government-owned mode in the land transportation system. It operates mainly full-sized units (fifty-five to sixty-five passengers), although there are some articulated units on more heavily trafficked routes as well as smaller buses for rural routes where roadway widths are more constrained. Although it has the lowest fares (it is subsidised by over three hundred million TT dollars annually), it is very unpopular, transporting less than five percent of transit users [7].

The maxi-taxi service is a privately owned, paratransit service that is heavily used by travellers. Maxi taxis are mini-buses which hold between nine to twenty-five passengers. Though unregulated, fares are set by loose associations of maxi-taxi owners. Each maxi-taxi can only operate in one of five regions in the county. They operate like unscheduled buses from established stands and on well-known routes within their regions. There are approximately five thousand maxi taxis on the island, with an estimated annual ridership of two hundred million passenger trips [7].

The route taxi is a privately owned vehicle, usually a sedan or a minivan seating four to eight passengers and like the maxi-taxi, is shared-ride and does not follow a schedule. The route taxis are registered as 'for hire' vehicles and carry a licence plate with H. Like the maxi taxis; associations set fares. Though taxis are not limited to any route, most operators work from stands and on well-known routes based on their residential location. There are approximately twelve thousand, five hundred route taxis with an estimated ridership of one hundred and twenty-five million passengers per annum [7]. Modes similar to maxi taxis and route taxis exist in many developing countries and SIDS [8, 9].

PH taxis, known as 'pirate taxis' are not registered for hire but operate without legal sanction. Indeed, since they are the same size and carry the same registration designation of "P", $\mathrm{PH}$ taxis 
are physically indistinguishable from private vehicles. They formerly operated in areas not well served by legal route taxis and maxi taxis. This mode shares similar characteristics to the route taxi; however, because it operates illegally, there is no restriction on the size of vehicles used or the routes they penetrate. Additionally, while legitimate taxi drivers require a special permit and a background check for criminal activity, $\mathrm{PH}$ drivers operate without such a permit.

Similarly, vehicles used as legal route taxis have to be inspected annually by the licensing authority and carry higher insurance premiums than PH cars. Consequently, since PH cars are operating illegally, their passengers are not insured against risk or injury. In recent times, these illegal taxis have competed aggressively with the route taxis and maxis and affected the livelihood of those operators.

This study examines the relationship between sociodemographic characteristics and the transportation system, specifically examining the different public transportation modes on the island of Trinidad, a Caribbean SIDS. The remainder of this paper discusses more details on the characteristics of a sample of Trinidad travellers and the results of a household travel behaviour survey.

\section{Study Area and Methodology}

The study focused on the North corridor of Trinidad, where the capital is located. The sample area was Trincity Development. One of the main reasons this area was selected was for its diverse socio-economic and demographic community. Furthermore, there are various transportation modes available to individuals in this area. For public transportation alone, there are multiple modes available to users; bus, and the paratransit systems of the 'maxi-taxi', taxi, and the illegally operated 'ph taxis'. These characteristics have made the area attractive for selecting individuals to administer the survey instrument.

Trincity is a relatively large area consisting of multiple enumerator districts. To collect the required sample size of respondents, the area was further stratified. The study area was bounded by the following roads, as shown in Fig. 1; Eastern Main road at the north, Churchill Roosevelt Highway at the south, Orange Grove Road at the west and Trincity Central Road at the East. 
Faculty of Engineering, The UWI, St. Augustine I June $1^{\text {st }}-5^{\text {th }}, 2020$

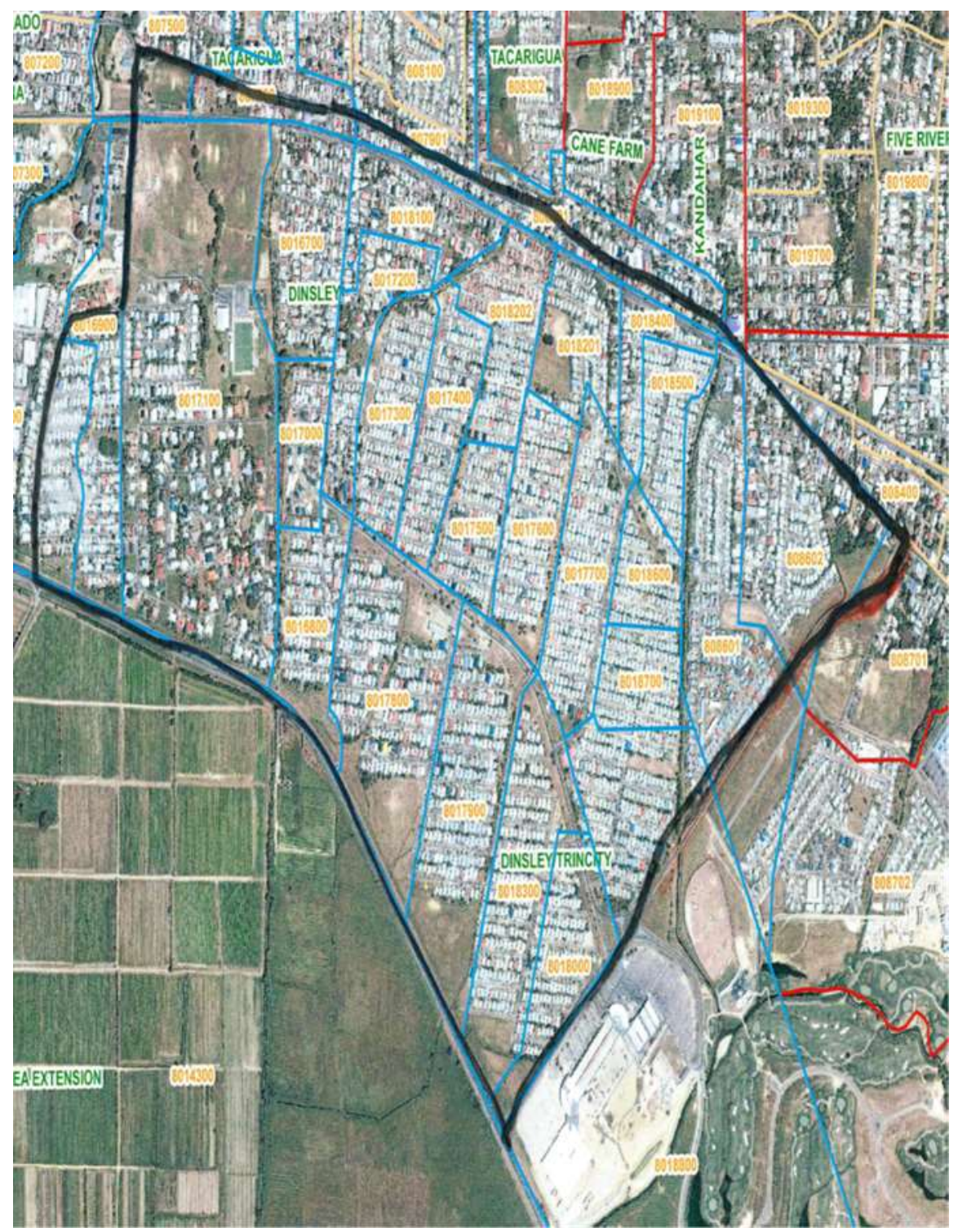

Figure 1: Boundary of the Study Area in Trincity, Trinidad

\section{Results and Discussion}

The data collected showed that most individuals worked within the same regional corporation that they lived (see Fig. 2). More than 50\% of the sample worked in the Tunapuna-Piarco Region, where Trincity is located. On a smaller scale, the most popular towns for the destination trips were Arouca, Tunapuna and Port of Spain. It was anticipated that most of the sample would work in the Port of Spain area, as this is the main central business district of Trinidad. 


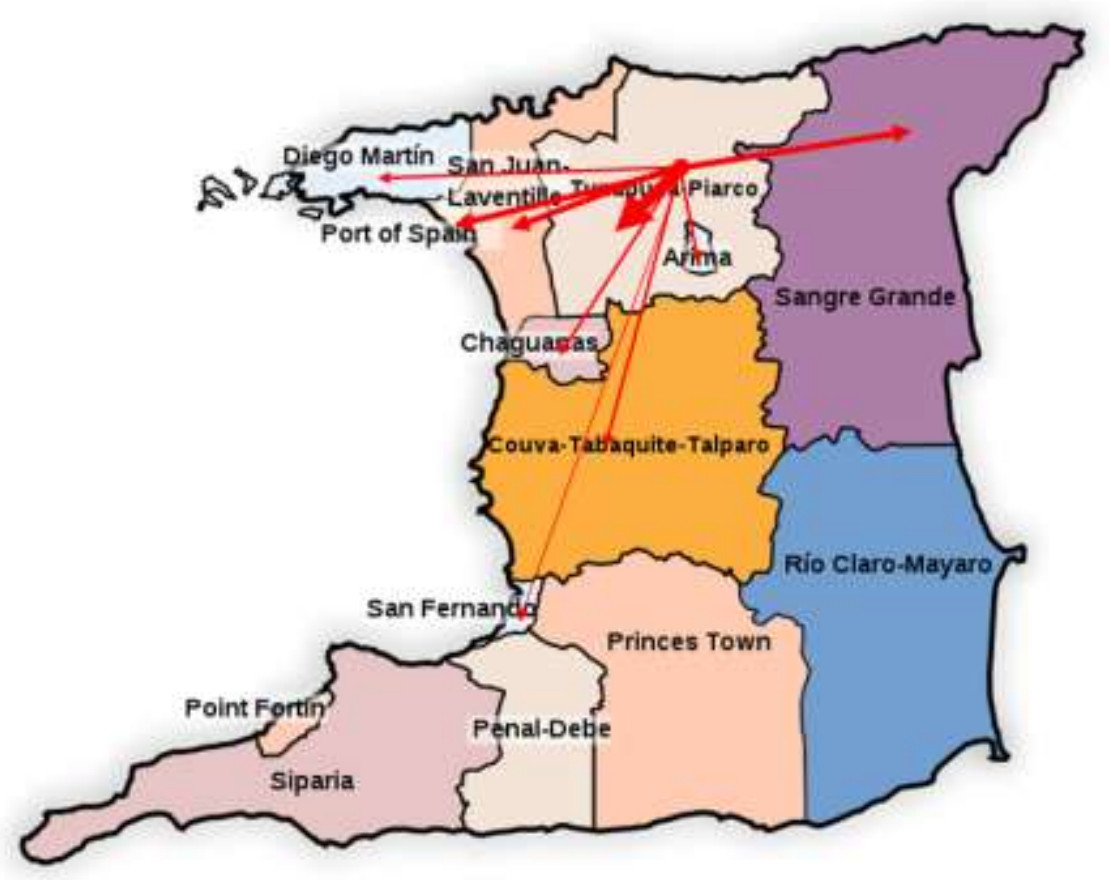

Figure 2: The location of the destination trips in the study

\subsection{Socio-economic and Demographic Characteristics of Respondents}

Just under one-half of the respondents (49\%) in the survey were women, whereas $48 \%$ were men, as highlighted in Fig. 3 and 3\% did not specify their gender. The age distribution of the sample showed that the sample consisted mainly of persons between the ages of 25-34 years of age (18.5\%), 35-44 years (33\%) and 45-54 years (29.3\%). Thus, it is assumed that most of the sample were mature persons with already established families, travel patterns and behaviours. Over $60 \%$ of the sample had a gross monthly income between TTD 10,000 and TTD 21,999, suggesting the majority of the sample is in the middle-class income bracket. 


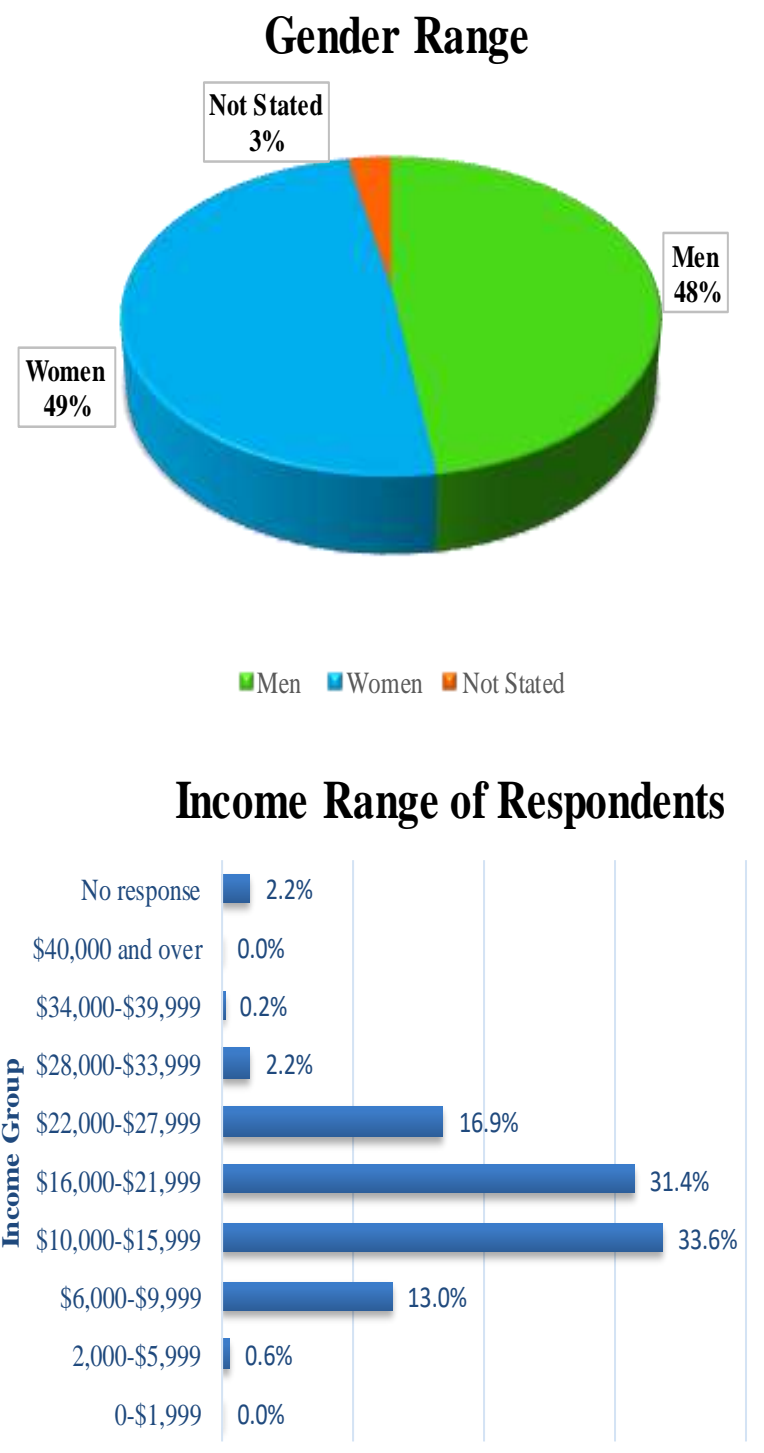

\section{Age Range of Respondents}

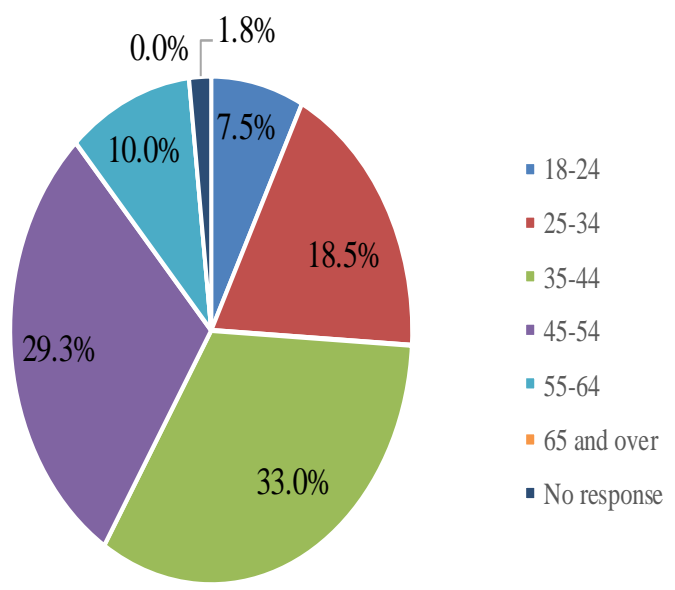

\section{Household Sizes of Sample}

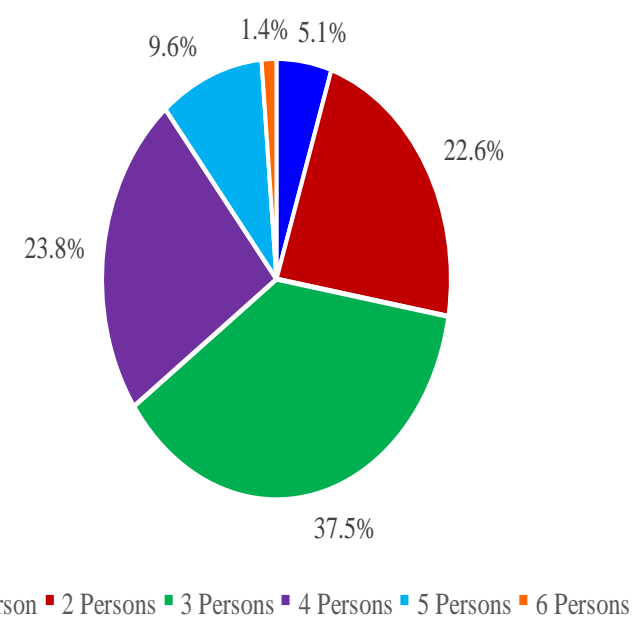

Figure 3: Socio-economic Characteristics of the sample

Within the entire sample, only $2.6 \%$ of persons responded saying there was no car in their household, whereas, $53.4 \%$ of the sample had two cars in their household and $31.9 \%$ had only one car as shown in Table 1. The average household size was three persons, and it was seen that most 2, 3 and 4 persons' households had as many as two vehicles available to them, with a few having six cars. 
Table 1: Number of vehicles in the household

\begin{tabular}{|l|l|l|l|l|l|l|l|l|}
\hline \multirow{2}{*}{ Household } & \multicolumn{6}{|l|}{ No of Vehicles in the Household } \\
\cline { 2 - 9 } & $\mathbf{0}$ & $\mathbf{1}$ & $\mathbf{2}$ & $\mathbf{3}$ & $\mathbf{4}$ & $\mathbf{5}$ & $\mathbf{6}$ & Grand Total \\
\hline $\mathbf{1 . 0 0}$ & 3 & 23 & & & & & & 26 \\
\hline $\mathbf{2 . 0 0}$ & 3 & 56 & 52 & 4 & & & & 115 \\
\hline $\mathbf{3 . 0 0}$ & 6 & 42 & 119 & 23 & 1 & & & 191 \\
\hline $\mathbf{4 . 0 0}$ & & & & & & & & \\
\hline $\mathbf{5 . 0 0}$ & & 28 & 74 & 14 & 5 & & & 121 \\
\hline $\mathbf{6 . 0 0}$ & 1 & 9 & 22 & 13 & 2 & 1 & 1 & 49 \\
\hline Grand Total & $\mathbf{1 3}$ & $\mathbf{1 5 9}$ & $\mathbf{2 7 2}$ & $\mathbf{5 5}$ & $\mathbf{8}$ & $\mathbf{1}$ & $\mathbf{1}$ & $\mathbf{5 0 9}$ \\
\hline & & 1 & 5 & 1 & & & & 7 \\
\hline
\end{tabular}

A large percentage of the respondents, recorded using a private car for their work journeys. More than $80 \%$ of persons had private car tours in their typical workday, as shown by Fig. 4 . Whereas, $12 \%$ of the sample had public transportation tours and $5 \%$ used shared-ride tours in their typical workday. Shared rides are defined as private car tours, where the individual is a passenger in the car and not the driver, whereas private car trips are defined as driver trips. In the study, the majority of private car tours were single-occupancy. Even though the public transportation users were a tiny percent, it is still necessary to analyse these users separate from the private car users. 


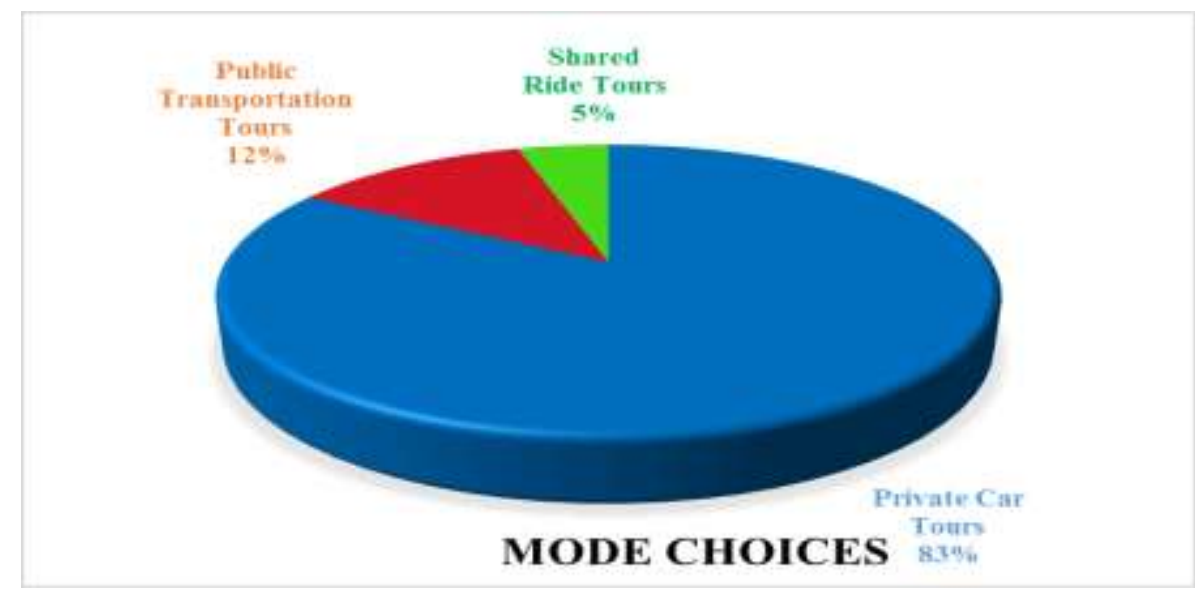

Figure 4: Modal Split of the Sample

The most popular mode used by public transportation users is the maxi-taxi, as shown in Fig. 5 . This is expected since most of the work tours of the sample area on the East-West corridor, where the maxi-taxi is very popular. The next popular tour is a mixed tour. This is classified where one leg of the individual's journey is by private car, and the other leg, by public transportation. There were also a few cases where the individual used two different modes in the entire journey. It was necessary to classify these tours exclusively, since most persons, use the same primary mode, to and from work. Thus, the use of two different modes, especially where one is a private car, was unique. Also noteworthy, was that for the Mixed Tours, it was the journey to work that was the shared-ride, while the journey from work to home in the evening was by public transportation. Even though the bus and walk tours were not as popular, a small percentage still used these modes. Those persons that walked lived within proximity to their jobs.

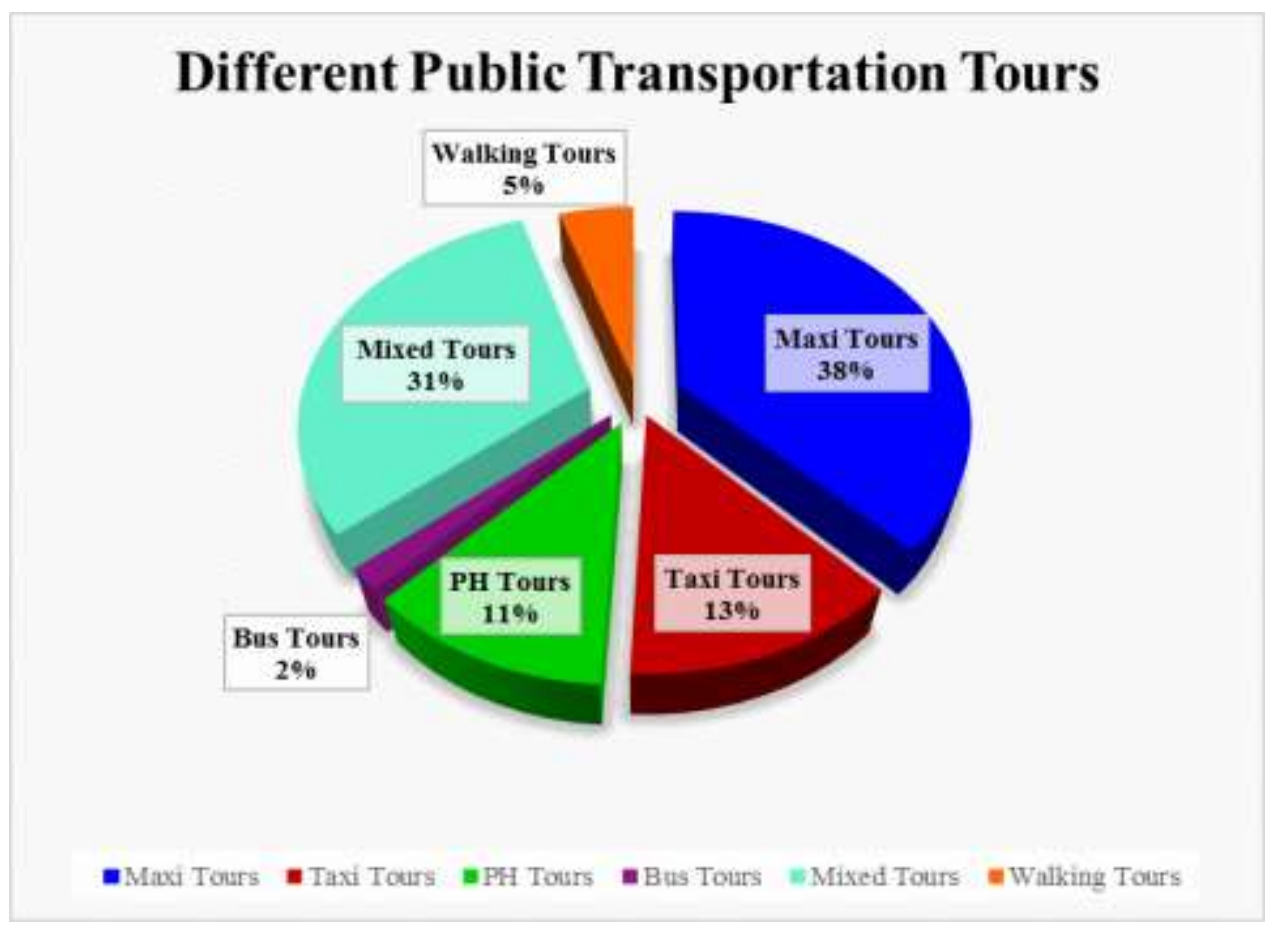

Figure 5: Public Transportation tours in the sample 
As stated previously, most tours of the public transportation users consisted of mainly 2 or 4 trips. These trips have a sequence of home to work, and back home for the two-trip tour. However, for the 4-trip tours, persons made a stop somewhere to switch modes, usually from walking, to some motorised mode, as shown in Table 2. There was also a small percentage of persons who made 6 trips during their daily work commute. Generally, only two of these trips were by a motorised vehicle, while the remaining four were generally by walking. These walking trips were to and from the max/bus stop. Therefore, the location of the maxi/bus stops acted as a transfer hub for these persons.

Table 2: Trip pattern of public transportation users

\begin{tabular}{|l|l|}
\hline $\begin{array}{l}\text { Number of Trips in the } \\
\text { Tour }\end{array}$ & Typical Pattern of Public Transportation Users \\
\hline $\mathbf{2}$ & Home----Work----Home \\
\hline $\mathbf{3}$ & $\begin{array}{l}\text { Home----Work----Maxi/Bus Stop----Home } \\
\text { Home----Maxi/Bus Stop----Work----Maxi/Bus Stop----Home }\end{array}$ \\
\hline $\mathbf{6}$ & $\begin{array}{l}\text { Home----Maxi/Bus Stop----Maxi/Bus Stop----Work---- } \\
\text { Maxi/Bus Stop----Maxi/Bus Stop----Home }\end{array}$ \\
\hline
\end{tabular}

\subsection{Tour Characteristics of Travellers}

The data collected in this research revealed that public transportation users and private car users have very different tour patterns. The data highlighted that though both groups of travellers indicated having multiple trips on a tour. A 'stop' with public transportation users indicated a change a mode, while a 'stop' with private car users indicated a change in purpose. The different tour behaviours need to be focused in more detail to gain a better understanding of the users

Public transportation users tend to make mostly 2-trip and 4-trip tours, as shown in Table 3. However, Table 4 exhibits that the majority of private car tours were 2-trip tours. Now, with the public transportation users, there was a trip length variety of up to 7 trips in one tour. However, with the private car, the longest reported tour, was four trips. The individual that indicated the 7 trip tour was an anomaly. This respondent displayed that they made a stop, with a change in purpose, during their work tour, thus increasing the number of transfers and inevitably the cost of the trip. The occurrence of having multiple stops in a public transportation tour is a disincentive to using it and makes the private car more attractive. 
Table 3: Tour lengths of public transportation users

\begin{tabular}{|l|r|}
\hline \multicolumn{2}{|c|}{ Public Transportation Users } \\
\hline Tour Length & Percentage \\
\hline 2 trips & $38 \%$ \\
\hline 3 trips & $15 \%$ \\
\hline 4 trips & $36 \%$ \\
\hline 5 trips & $2 \%$ \\
\hline 6 trips & $8 \%$ \\
\hline 7 trips & $2 \%$ \\
\hline
\end{tabular}

Table 4: Tour lengths of private car users

\begin{tabular}{|l|r|}
\hline \multicolumn{2}{|c|}{ Private Car Users } \\
\hline Tour Length & Percentage \\
\hline 2 trips & $70 \%$ \\
\hline 3 trips & $15 \%$ \\
\hline 4 trips & $13 \%$ \\
\hline Not Stated & $3 \%$ \\
\hline
\end{tabular}

Taking a closer look at the socio-economic demographics of the travellers, it was found that seventy-two (72\%) of the public transportation users were women, while forty-three (43\%) of the private car users were women. However, in both groups of travellers, women made more trips on their tours than men, as shown in Table 5 and Table 6 . This does correspond to the literature as women tend to make more trips than men. These stops usually involved dropping off or picking up the children, or other personal business for private car tours.

Table 5: Length of public transportation tours made by gender

\begin{tabular}{|l|r|r|r|r|r|r|r|}
\hline \multirow{2}{*}{ Gender } & \multicolumn{7}{|c|}{ Tour Lengths } \\
\cline { 2 - 8 } & 2 trips & 3 trips & 4 trips & 5 trips & 6 trips & 7 trips & Total \\
\hline Man & $17 \%$ & $11 \%$ & $45 \%$ & $0 \%$ & $20 \%$ & $0 \%$ & $\mathbf{1 6}$ \\
\hline Woman & $83 \%$ & $89 \%$ & $55 \%$ & $0 \%$ & $80 \%$ & $100 \%$ & $\mathbf{4 4}$ \\
\hline $\begin{array}{l}\text { Not } \\
\text { Stated }\end{array}$ & $0 \%$ & $0 \%$ & $0 \%$ & $100 \%$ & $0 \%$ & $0 \%$ & $\mathbf{1}$ \\
\hline Total & $100 \%$ & $100 \%$ & $100 \%$ & $100 \%$ & $100 \%$ & $100 \%$ & $\mathbf{6 1}$ \\
\hline
\end{tabular}


Table 6: Length of private car tours made by gender

\begin{tabular}{|l|r|r|r|r|}
\hline $\begin{array}{l}\text { Count of No } \\
\text { of Trips }\end{array}$ & 2 trips & 3 trips & 4 trips & 5 trips \\
\hline Man & $59 \%$ & $38 \%$ & $33 \%$ & $100 \%$ \\
\hline Woman & $37 \%$ & $62 \%$ & $62 \%$ & \\
\hline Not Stated & $4 \%$ & $0 \%$ & $5 \%$ & \\
\hline Grand Total & $\mathbf{1 0 0 \%}$ & $\mathbf{1 0 0 \%}$ & $\mathbf{1 0 0 \%}$ & $\mathbf{1 0 0 \%}$ \\
\hline
\end{tabular}

Table 7: Length of public transportation tours by age group

\begin{tabular}{|l|l|l|l|l|l|}
\hline \multirow{2}{*}{$\begin{array}{l}\text { Tour } \\
\text { Length }\end{array}$} & \multicolumn{4}{|l|}{ Age } \\
\cline { 2 - 6 } & $\mathbf{1 8 - 2 4}$ & $\mathbf{2 5 - 3 4}$ & $\mathbf{3 5 - 4 4}$ & $\mathbf{4 5 - 5 4}$ & $\begin{array}{l}\text { Not } \\
\text { Stated }\end{array}$ \\
\hline $\mathbf{2}$ trips & $26 \%$ & $22 \%$ & $39 \%$ & $9 \%$ & $4 \%$ \\
\hline $\mathbf{3}$ trips & $22 \%$ & $44 \%$ & $33 \%$ & $0 \%$ & $0 \%$ \\
\hline $\mathbf{4}$ trips & $59 \%$ & $14 \%$ & $23 \%$ & $5 \%$ & $0 \%$ \\
\hline $\mathbf{5}$ trips & $0 \%$ & $100 \%$ & $0 \%$ & $0 \%$ & $0 \%$ \\
\hline $\mathbf{6}$ trips & $0 \%$ & $60 \%$ & $0 \%$ & $40 \%$ & $0 \%$ \\
\hline $\mathbf{7}$ trips & $0 \%$ & $0 \%$ & $100 \%$ & $0 \%$ & $0 \%$ \\
\hline
\end{tabular}

It was also seen that the tour lengths varied by age and by household size, as shown in table 7 . Individuals in the 25- 34 age group made a wider variety of tour lengths than any other group, while persons in the 18-24 group made at most 4 trips, in a tour. Also noteworthy, the 45-54 age group made predominantly 6-trip tours.

Respondents were also able to give information on what they perceived to be the next feasible alternative in the data set if the mode they used that day was not available to them. The choice behaviour of private car users and public transportation users had similarities and differences in this regard. In both cases, the taxi was the most popular alternative and the bus the least popular public transportation mode. Furthermore, though the ph and registered taxis share numerous similarities, the ph was one of the least desirable alternatives by both traveller types.

Within public transportation users, the maxi-taxi was the most popular mode. Therefore, for many persons, if this mode was not available, the next practical option was the registered taxi. Though many of these public transportation users did indicate being from a household with a car, a large percentage did not regard the car as a feasible option for the alternative. This suggests that though a car was available, it may generally be used by someone else in the household.

In most cases, the main reason for not selecting the ph was because it was not accessible to the users. This suggests that though the ph is heavily utilised throughout different areas of the country, 
it is not as common in the Tunapuna-Piarco Region. This may be because many of the feeder routes are already well catered for by route taxis, and PHs are more prevalent in routes not served by taxis or maxis.

In analysing the alternatives chosen by the private car users, some interesting facts were highlighted. Though the bus was the highest-rated public transportation mode for safety and comfort, among the private car users, it was the least reported on as a feasible alternative. The main reason for this was time, suggesting that many persons did not find the service reliable. They also listed comfort as another big reason for not choosing the bus. Many persons critiqued the maxi-taxi for similar reasons as to why it was not an option. Similar to transit users, the private car users listed the reasons for not choosing the ph taxi was accessibility and comfort. Overall, comfort and time were the two most important reasons to car users, for not selecting a mode. The public transportation users listed their main reason for not selecting a specific mode was the lack of availability. This suggested that although to the analyst, the sample had all modes in the choice set available to them, practically the respondents did not feel this way and therefore neglected specific modes because taking them was infeasible. This behaviour was seen throughout the survey, where persons did not give information on modes that they thought were not practical to them.

\section{Conclusion}

This paper highlighted some exciting characteristics of the sample of Trinidadians used for this survey. The survey sample is overall homogenous in age, income and household size. The majority of the sample, an overwhelming $97 \%$ have at least one vehicle in the household. However, about $83 \%$ of the sample used private car tours, $12 \%$ used public transportation and $5 \%$ were purely shared-ride. Though this split does not mimic the national modal split for the East-West corridor, it still gave a large amount of information to be analysed.

One notable finding was that the PTSC Bus was the least used motorised mode in the choice set and the most under-reported alternative mode. Many respondents, both public transportation and private car users, reported availability as the main reason for not using the PTSC mode. This suggests that if this feature were improved, PTSC Bus ridership would increase.

Most of the public transportation users were women, whereas men were the most dominant private car users. Also, notable is that most private car tours were two trips long, home to work and back. However, the average public transportation tour was 4 trips long, where two of the trips were generally non-motorised, walking trips. Further worthwhile mention is the fact that stops differ between public transportation and private car users. Private cars tend to make multiple stops, where a stop indicates a change in purpose, while public transportation users indicated stops as a change in mode, and they had a single-purpose tour.

This paper set the foundation for understanding travel behaviour and trip patterns in Trinidad, and though a mode choice model is needed for conclusive results, this paper supports some of the findings in the literature and highlight notable behaviour traits in Trinidadians. 


\section{References}

[1] Briguglio, L., Small island developing states and their economic vulnerabilities. World development, 1995. 23(9): p. 1615-1632.

[2] Gay, D., T. Rogers, and R. Shirley, Small island developing states and their suitability for electric vehicles and vehicle-to-grid services. Utilities Policy, 2018. 55: p. 69-78.

[3] Cervero, R., Linking urban transport and land use in developing countries. Journal of Transport and Land Use, 2013. 6(1): p. 7-24.

[4] Shimazaki, T. and M. Rahman, Physical characteristics of paratransit in developing countries of Asia. Journal of advanced transportation, 1996. 30(2): p. 5-24.

[5] Vuchic, V.R., Urban public transportation; systems and technology. 1981.

[6] Chowdhury, T.D., et al., Identifying important features of paratransit modes in Sylhet City, Bangladesh: a case study based on travelers perception. Civ Eng J, 2018. 4(4): p. 796-811.

[7] Steer Davies Gleave, Trinidad Rapid Rail Transit System: Socio-Economic Analysis Report. 2008. p. 71.

[8] Cervero, R., Informal transport in the developing world. 2000: UN-HABITAT.

[9] Joewono, T.B. and H. Kubota, The characteristics of paratransit and non-motorized transport in Bandung, Indonesia. Journal of the Eastern Asia Society for Transportation Studies, 2005. 6: p. 262-277. 